\title{
Harmonic Elimination Using Three Phase Shunt Active Power Filter In Distribution System Consisting of BLDC Drive Load
}

\author{
SVD Anil Kumar ${ }^{1}$ \\ Assoc.Prof, EEE Department, \\ St.Ann's College of Engineering and Technology, Chirala, Andhra Pradesh. \\ svdanil@gmail.com \\ Dr.K.Ramesh Reddy ${ }^{2}$ \\ Principal, G Narayanamma Institute of Technology and Science, \\ Shaikpet, Hyderabad, Telanganna. \\ kollirameshreddy@yahoo.com
}

\begin{abstract}
Brushless DC (BLDC) motors are increasing their prominence in these modern days due to its reduced complexity and increased efficiency. Brushless DC motors need a front-end converter for its electronic commutation. Brushless DC motors when connected to power system induces harmonics in source components due to presence of front-end non-linear power electronic converter. Non-linear loads induce harmonics and can cause serious affects to the other loads connected at point of common coupling. Shunt active filter is a custom power device employed for compensation of harmonics to maintain source parameters unaffected due to non-linear load. Shunt active filter for harmonic compensation is controlled with instantaneous active and reactive power theory. The system was tested by placing brushless motor drive load at different nodes and is simulated using MATLAB/SIMULINK and results are presented.
\end{abstract}

Keywords: Brushless DC Motor (BLDCM), Harmonics, Shunt Active Filter (SAF), Drive, Compensation.

\section{INTRODUCTION}

Electric drive systems are regularly used in several applications like, irrigation system, air-conditioning, regular or hybrid electric vehicles, elevators, in every aspect of daily living application, etc. Any electric drive system works based on the transformation of electric energy to mechanical energy at variable speed situations [1]. The electric drive system comprised of electric motor, control apparatus, high-rated power converter and other sensing devices. Coming to electric motors, it was differentiated as DC motor, AC motor, Special applied motors. DC motor consists of shunt type, series type, compound type and AC motor consists of synchronous \& induction motors.

The DC motors over AC motors acquires many advantages like non-presence of commutator \& brush, low cost, low maintenance, weight/torque ratio, torque/inertia ratio. It is suitable for all areas \& environments, unrestricted on high range of voltage-power ratings \& easy speed control action. Special applied motors are variable reluctance motor, stepper motor, permanent magnet synchronous motor, brushless DC motor. Among all other motors, brushless DC motor (BLDC) plays a key role in industrial, commercial, automotive applications [2]-[5].

The BLDC motor as similar operation of permanent magnet synchronous motor (PMSM), but the cost is very low and needs simple operating stages. It is utilized highly for high range speeds-low power rated drive systems acts as the servo application, in place of DC servo motor. BLDC motor drive comes under modern drive analogy, because of using high rated power electronic technology with respect to digital control schemes over the electro-mechanic energy transformation processes [6]. Due to this high rated power semiconductor devices affects the power quality terms and creates harmonic/power pollution in a power distribution system.

For minimization of these harmonized components in three phase distribution systems using several ways. In that, identification of harmonics acts as a primary task [7]-[9] and then, compensation takes place as a secondary task [10]. Before harmonic compensation, measurement of harmonic is one of the familiar aspects of the power quality monitoring \& effective control. Based on several issues in formal schemes author explores a new advanced tool for harmonic measurement/elimination is named as "Total Harmonic Power method'/Active Compensation method. These are more convenient $\&$ advanced schemes and implemented in a three phase power distributed systems considering as a both linear load \& non-linear load placed at a two node formation as load shifting at conferred source node with respect to RL. The reliable harmonic identification is done by using THP method in a three phase distribution system fed BLDC drive. By utilizing Active Power Filter with effective current controller is best suited for harmonic compensation in a three phase distribution system based drive application. 
The paper presents Shunt active filter, a custom power device employed for compensation of harmonics to maintain source parameters unaffected due to non-linear load. Shunt active filter for harmonic compensation is controlled with instantaneous active and reactive power theory. The system was tested by placing brushless motor drive load at different nodes and is simulated using MATLAB/SIMULINK and results are presented.

\section{II.BRUSHLESS DC (BLDC) MOTOR}

The main disadvantages in conventional DC motors is; it needs commutator \& brushes regularly it have more maintenance. The spark generation is more effective at commutator $\&$ brushes regions and also un-utilized in exploitation areas, requires more space \& huge weight/torque ratio, etc [1]. Based on these deficiencies the formal DC motor is non-residence for many applications and unique solution is overcome in place of DC motor. The unique solution is by implementing brush-less DC motor drive system and doesn't require any mechanical commutator. Solid state switching devices are implanted under the commutator named as electronic commutator which is regularly called as interfacing inverter and brushes; it requires free maintenance service \& high efficiency [5].

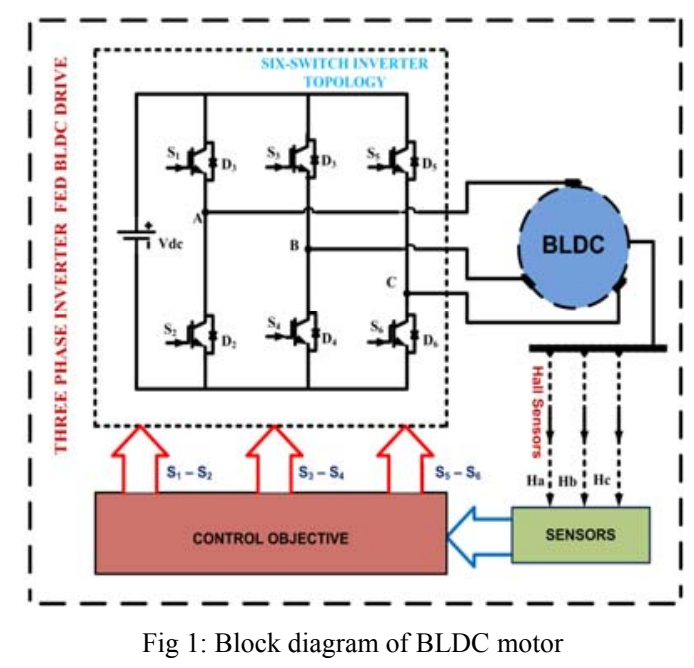

The construction of BLDC motor is very simple, the stator comprises of electromagnets and it has 4 electromagnets under its perimeter, implanted as a cross pattern style by a $90^{\circ}$ apart. The rotor comprises of pure magnets, it never requires any electrical windings and getting high efficiency due to low loss, un-interaction with brushing system. Block diagram of BLDC motor is shown in figure 1. The BLDC drive motors are two flavours such as sinusoidal type and trapezoidal type; these are critically evaluated under the BLDC construction design [6]. The sinusoidal type BLDC motor has pure sine nature back-EMF; it requires phase currents as sinusoidal nature for reducing ripple free torque performance. Coming to trapezoidal type BLDC motor has trapezoidal nature back-EMF and the quasi-square phase currents are required for ripple free torque performance.

The determination of back EMF should be distributive nature of rotor magnetic conditions \& stator windings. The BLDC drive is floated with a high reliable position encoder for sensing of rotor position by every instant of time. Various BLDC configurations are reviewed, in that three phased BLDC motor drive plays a prominent role in several applications due to low torque ripple \& greater efficiency. The power switching devices helps to regulate the stator currents for attaining precise \& reliable control action. The rotor position is sensed by enhancing hall sensors, integrated at shaft consisted of low range magnets. The operating principle of BLDC drive motor is same as classic brushed type DC motor.

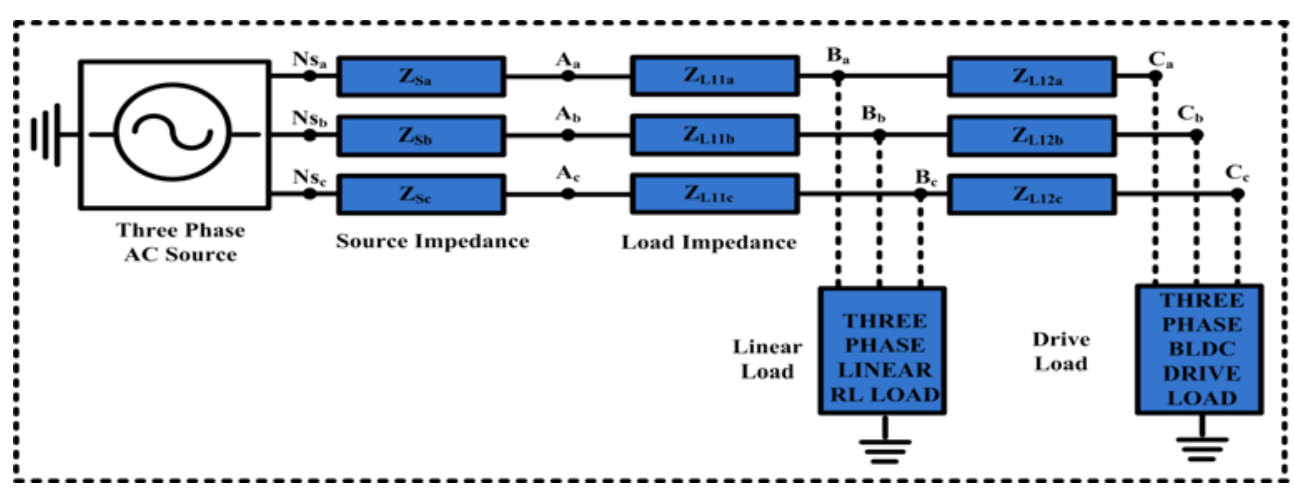

Fig 2: Three Phase Drive Load Placed at Load Side with Specific Load Impedance at Node C 


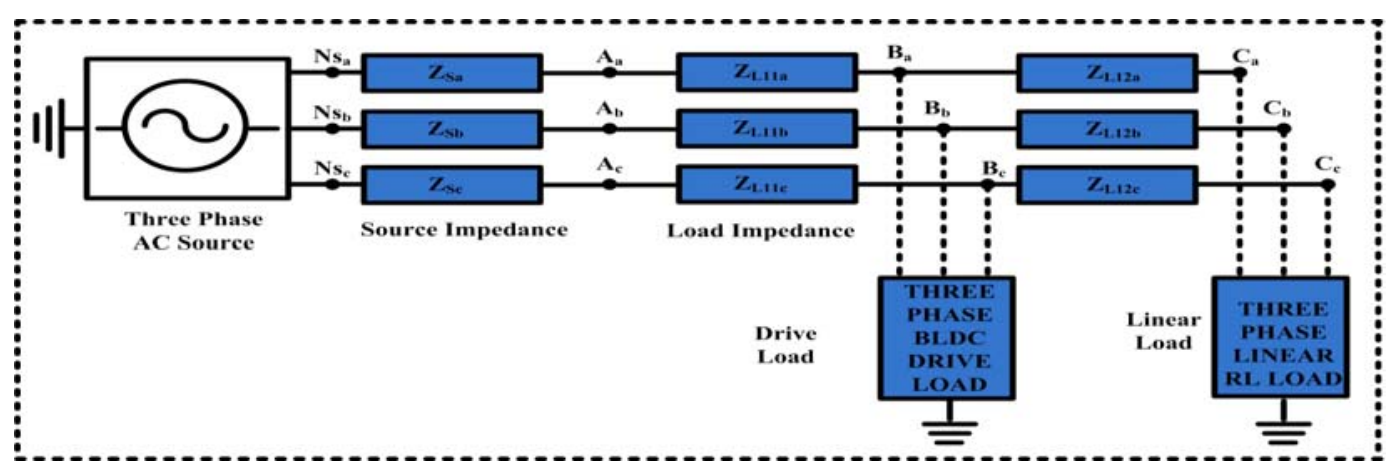

Fig 3: Three Phase Drive Load Placed at Load Side with Specific Load Impedance at Node B

\section{HARMONIC IDENTIFICATION}

Now-a-days, the power distribution system is troubled from the harmonic pollution prompted by modern drive systems which are effectively operated by power electronic devices. Due to this harmonic pollution effects the power quality standards at PCC level and the harmonic existence are super-imposed on fundamental frequency. Harmonic identification in a power distribution system obtains key significance for illustrating harmonic perpetrators for eradicating the harmonics by superior compensation technology.

Harmonic identification is the primary task for identification the range of harmonic values and harmonic compensation takes place as secondary task. In three phase system identify the $5^{\text {th }} \& 7^{\text {th }}$ harmonics only sue to presence of inter-harmonics and calculated for whole harmonics.

Figure 2 shows the power system with Three Phase Drive Load Placed at Load Side with Specific Load Impedance at Node $\mathrm{C}$ and figure 3 shows the power system with Three Phase Drive Load Placed at Load Side with Specific Load Impedance at Node B.

\section{IV.HARMONIC COMPENSATION WITH SHUNT ACTIVE FILTER}

The active power filtering technology have been implemented, characterised and priced in several past years ago. Mostly, they are highlighted as compensation of voltage and current reflected distortions like voltage harmonics, voltage swells \& sags, flickers and current harmonics, elimination of neutral current, reactive power control, etc. Moreover, active filters are comprised of two categorized as three phase, single phase filtering systems. Single phased filtering technique is highly used to enhance power quality concerns which are related to single phase loads. Coming to three phased active power filtering (APF) technique is regularly used in high power range three phased non-linear loads like AC-DC conversion topologies, arc furnaces, adjustable speed drives, HVDC transformation etc. With respect to specific topologies, APF is comprised as voltage source inverter (VSI) type and Current Source Inverter (CSI) type active filters.

The selection of APF is effectively decided based on the concern \& supply system, the VSI APF technique is regular technique, and used in both single-three phased system. In VSI type storage battery or DC capacitor acts as the source of the VSI-APF and in CSI type inductor acts as the source of the CSI-APF. Over the two topologies, VSI-APF is less expensive, easy control, lighter compare to CSI-APF. Another selection of APF is effectively decided by type of connection like as shunt APF, series APF and hybrid APF. The APF selection is merely recognized by depending of compensation principle, in that shunt APF is more capable of harmonic eradication from the source/PCC level with respect to effective control objective.

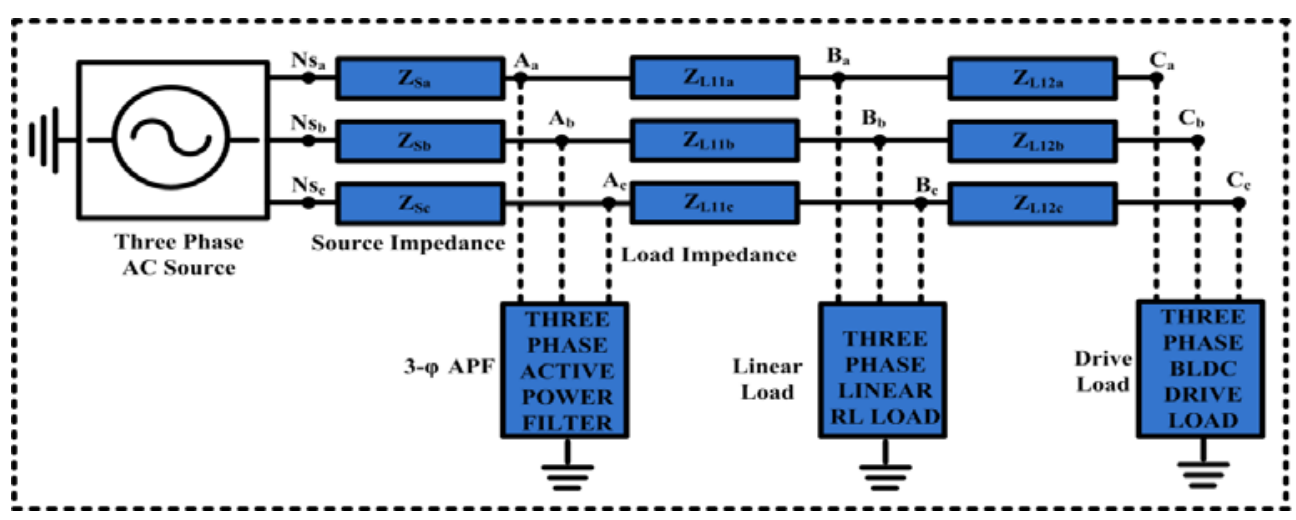

Fig 4: Three Phase Drive Load Placed at Load Side with Specific Load Impedance at Node C, the Three-Phase APF is interfaced at node A. 


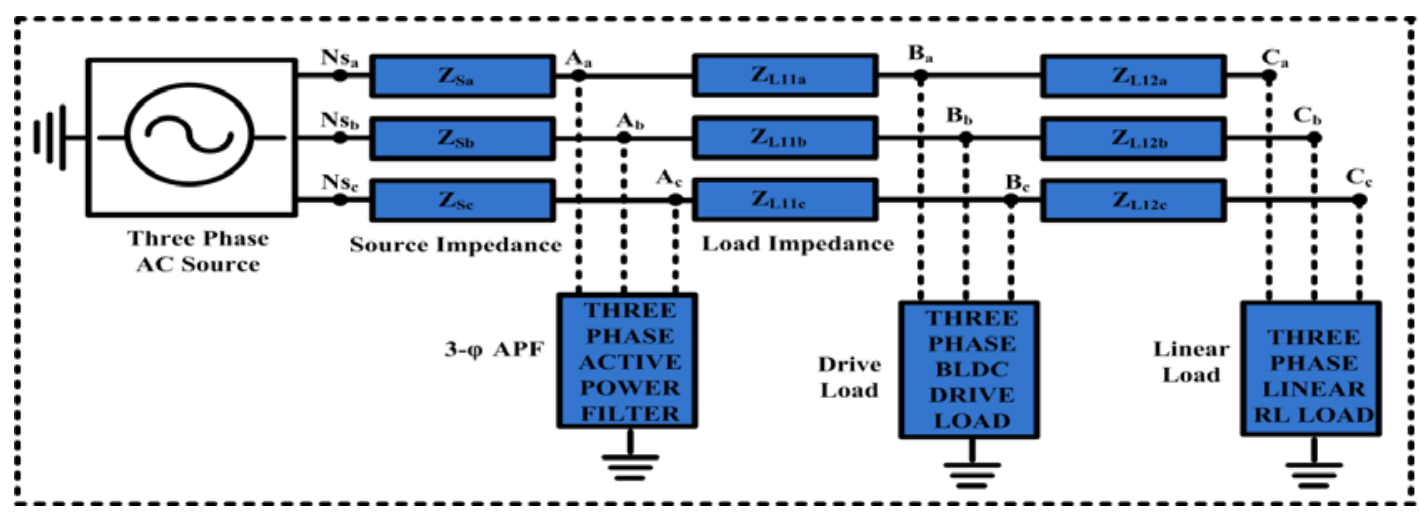

Fig 5: Three Phase Drive Load Placed at source Side with Specific Load Impedance at Node B, the Three-Phase APF is interfaced at node A.

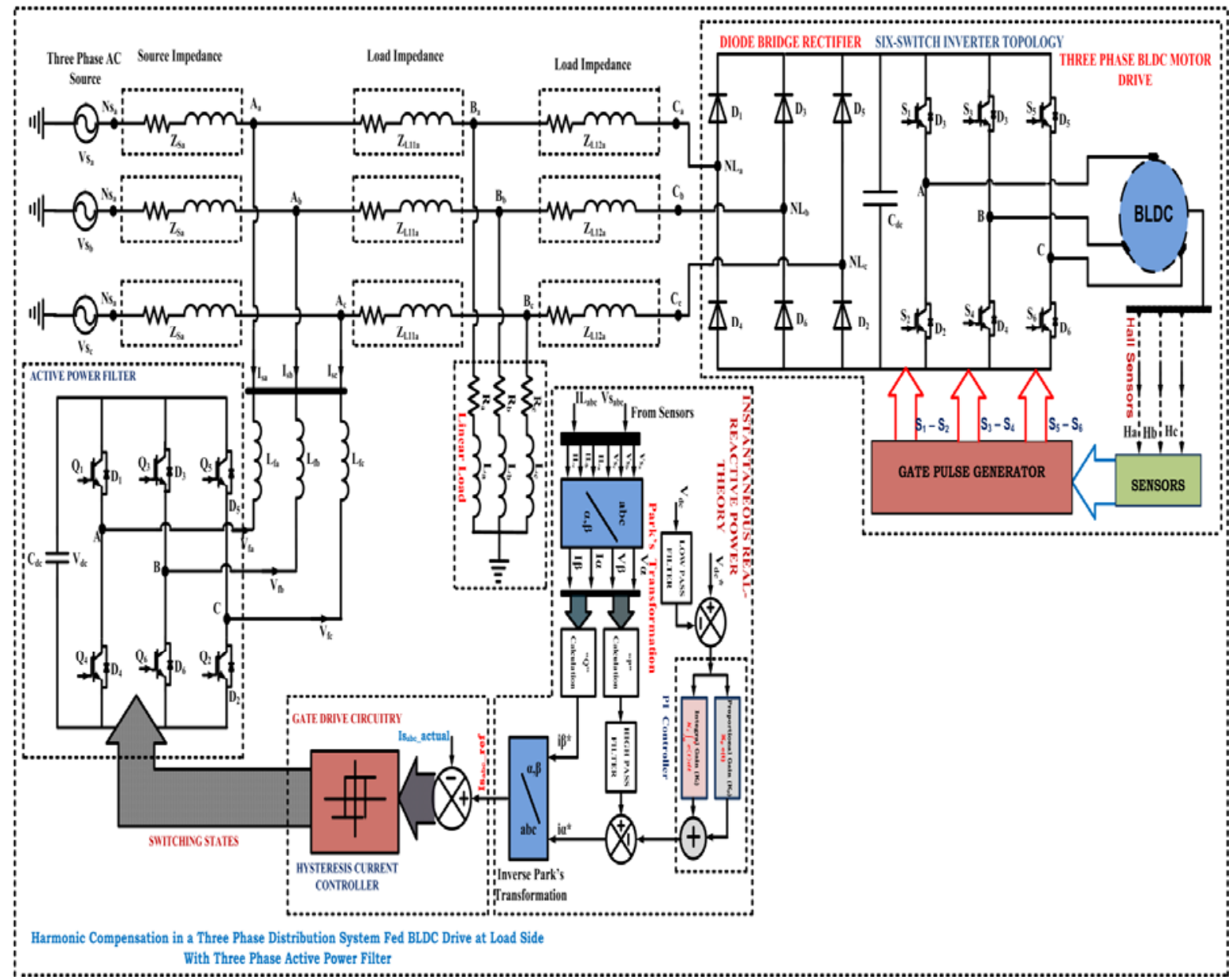

Fig 6: Schematic Diagram of Active Harmonic Compensation in a Three Phase BLDC Drive Load Placed at Load side with AC-DC/DC-AC Conversion Scheme Integrated by a Three Phase AC Source

Figure 4 shows three Phase Drive Load Placed at Load Side with Specific Load Impedance at Node C, the Three-Phase APF is interfaced at node A. Figure 5 shows three Phase Drive Load Placed at source Side with Specific Load Impedance at Node B, the Three-Phase APF is interfaced at node A. The selection of APF is effectively decided based on the concern \& supply system, the VSI APF technique is regular technique, and used in both single-three phased system. In VSI type storage battery or DC capacitor acts as the source of the VSI-APF and in CSI type inductor acts as the source of the CSI-APF. Over the two topologies, VSI-APF is less expensive, easy control, lighter compare to CSI-APF. The APF selection is merely recognized by depending of compensation principle, in that shunt APF is more capable of harmonic eradication from the source/PCC level with respect to effective control objective. 


\section{V.INSTANTANEOUS REACTIVE POWER (IRP) THEORY FOR CONTROL OF SHUNT ACTIVE FILTER}

The main principle of active compensation is to make a VSI by sinusoidal subtraction of load harmonics which is greatly recognized to regulate the particular load harmonized components. The compensation principle of three phased VSI-APF is based on reference current generation by advanced instantaneous Real (P) \& Reactive (Q) power theory; it supports better compensation characteristics in transient \& steady states. It will generates the required reference currents to minimize the current harmonics, maintain required DC bus capacitor voltage as constant and reactive control action.

The reference currents coming from IRP theory is transform to actual currents to make sufficient reference signal to the gate drive circuitry. Several gate drive circuits are used to generate switching states to VSI for attaining good compensation characteristics, in that Hysteresis Current Controller (HCC) is best suited for three phase active filtering technique. The HCC generates the switching states which are operated on limitation of upper/lower hysteresis current loop with respect to reference current signal. The attained switching states are transforming to VSI for the firing of voltage source inverter. This VSI eradicates the harmonics coming from the non-linear load and maintain PCC terms are qualified RMS nature \& limitation of harmonics as in IEEE standards.

\section{RESULTS AND DISCUSSIONS}

TABLE.1. Simulation Parameters

\begin{tabular}{|c|c|}
\hline Parameters & Value \\
\hline Source Voltage & $415 \mathrm{~V}$ \\
Fundamental Frequency & $50 \mathrm{~Hz}$ \\
Source Impedance & $(0.1+\mathrm{j} 0.9) \Omega$ \\
Load Impedance & $(0.5+\mathrm{j} 12.56) \Omega$ \\
DC Link Capacitor & $1500 \mu \mathrm{F}$ \\
Linear Load & $(100+\mathrm{j} 62.8) \Omega$ \\
\hline
\end{tabular}

A. Without Compensation
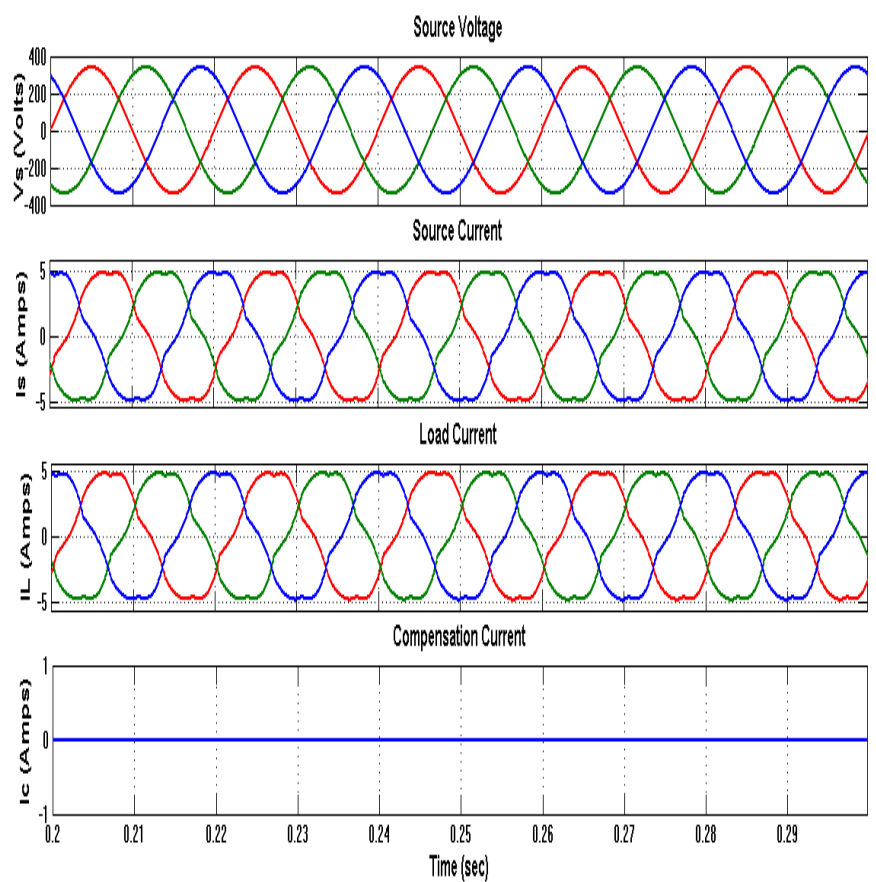

Fig 7: Source Voltage, Source Current, Load Current and Compensation currents of power system without APF 


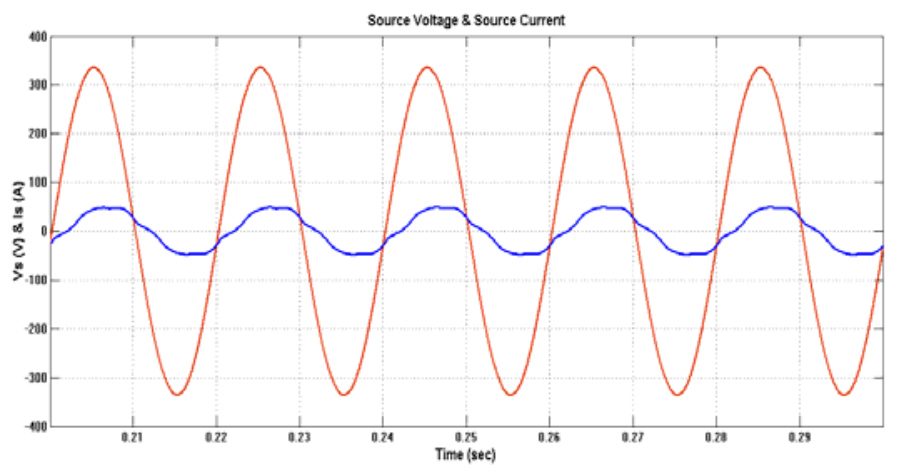

Fig 8: Power factor angle between Source Voltage and Source Current of power system without APF

Figure 7 shows the source Voltage, Source Current, Load Current and Compensation currents of power system without APF. Without compensation the source voltage is well within limits maintained without distortion. But the source current is distorted due to the presence of harmonics. Load current contains harmonics as load is of non-linear type. Compensation currents are zero as no compensator is present. Figure 8 shows the power factor angle between Source Voltage and Source Current of power system without APF. Source voltage and current are out of phase indicating power factor is not maintained nearer to unity.

B. With Compensation
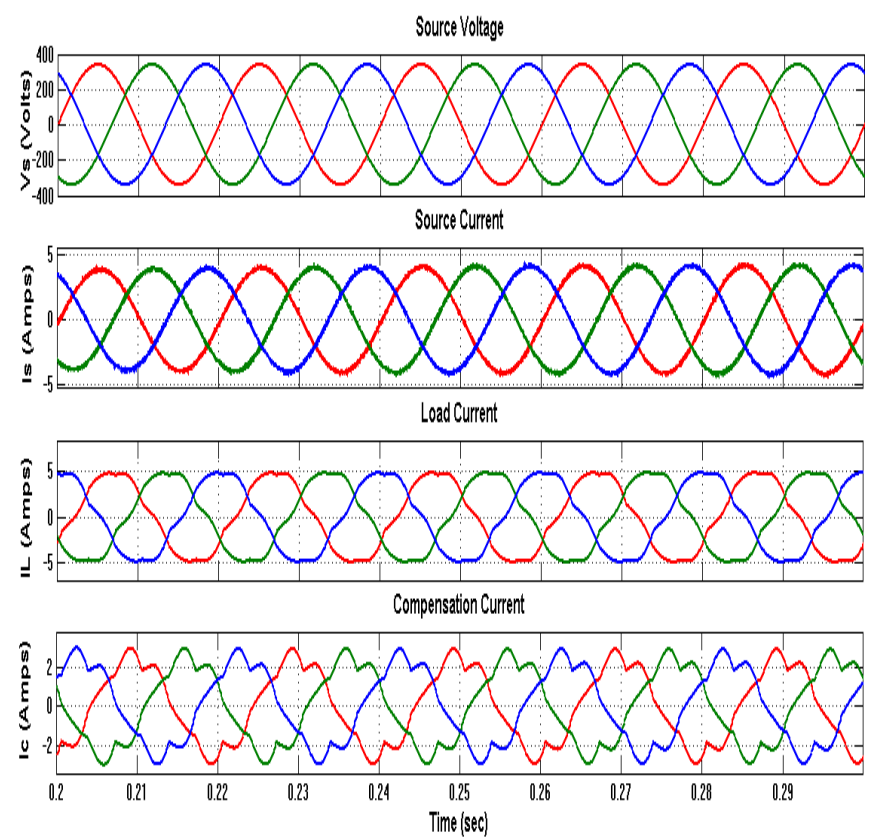

Fig 9: Source Voltage, Source Current, Load Current and Compensation currents of power system with APF

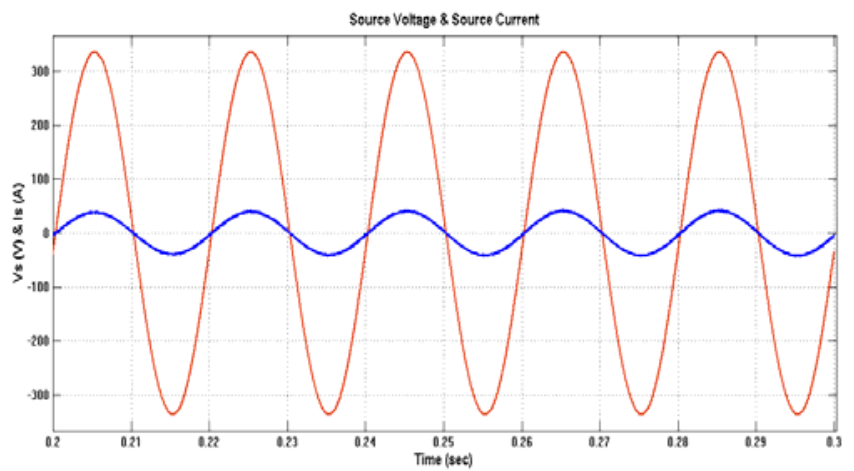

Fig 10: Power factor angle between Source Voltage and Source Current of power system with APF 
Figure 9 shows the source Voltage, Source Current, Load Current and Compensation currents of power system with APF. With compensation the source voltage is well within limits maintained without distortion and the source current is not distorted while harmonics are nullified with presence of APF. Load current is distorted and contains harmonics as load is of non-linear type. Compensation currents are shown which are sent from APF. Figure 10 shows the power factor angle between Source Voltage and Source Current of power system with APF. Source voltage and current are in-phase indicating power factor is maintained nearer to unity.
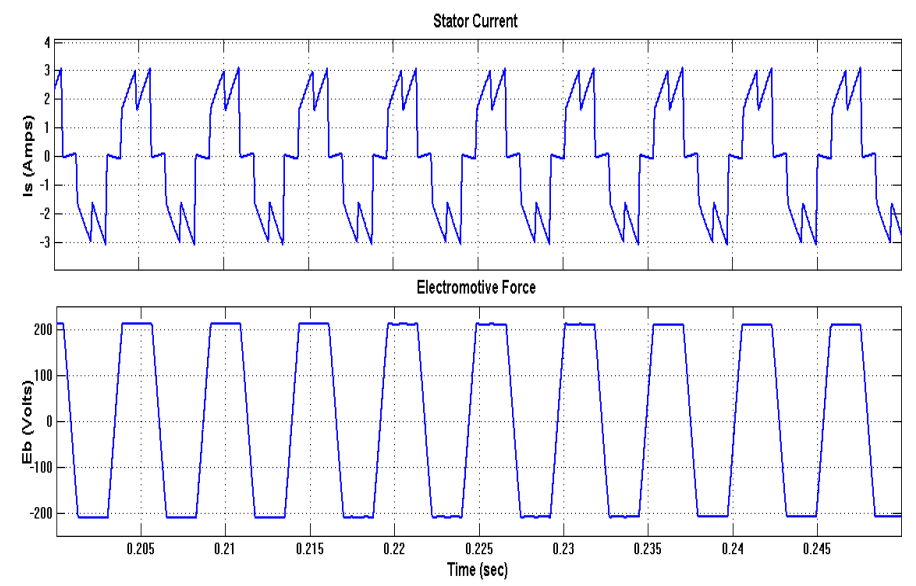

Fig 11: Stator current and Back EMF of BLDC motor

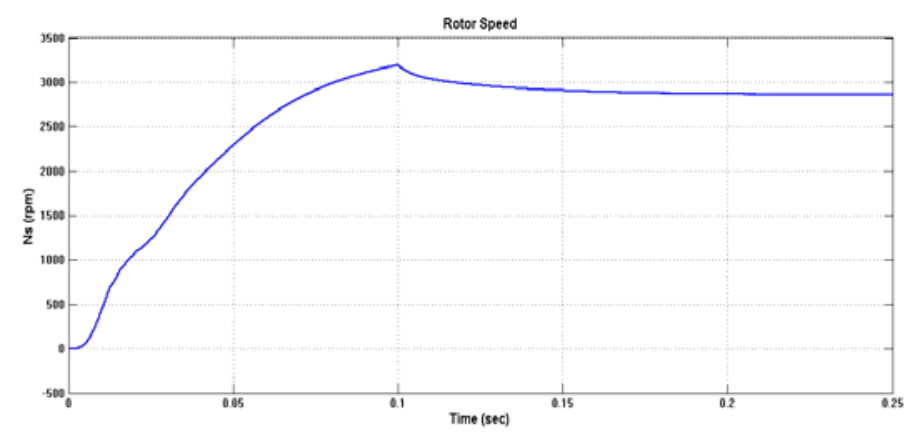

Fig 12: Speed of BLDC motor

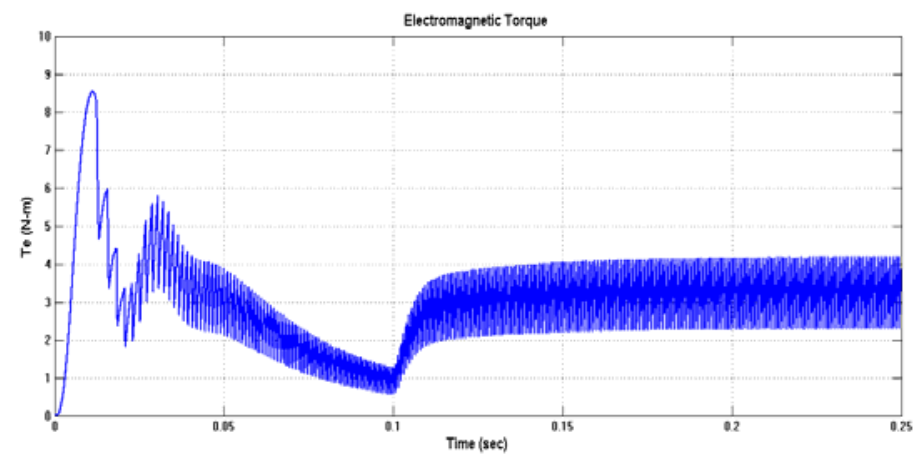

Fig 13: Torque of BLDC motor

Figure 11 shows the stator currents of BLDC and back EMF of BLDC motor. Figure 12 shows the speed of BLDC motor and speed is maintained at near 3000 RPM. Torque of BLDC motor is shown in figure 13.

\section{CONCLUSION}

This paper presents Shunt active filter, a custom power device for compensation of harmonics to maintain source parameters unaffected due to non-linear load. Shunt active filter for harmonic compensation is controlled with instantaneous active and reactive power theory. The system was tested by placing brushless motor drive load at different nodes and is simulated using MATLAB/SIMULINK and results are presented. Results shows the source currents with distortion when there is no APF for compensation and also the source currents with compensation where there is no distortion. Active power filter works good for harmonic compensation with BLDC motor load. 


\section{REFERENCES}

[1] S. Wiak, Brushless DC Permananet Magnet Motor for Electric Bike and their Impulse System for Battery Charging, International Journal of Electrical Engineering in Transportation, vol. 1, no. 1, 2005

[2] M. V. Ramesh, Speed Control Of Brushless Dc Motor By Using Fuzzy Logic Pi Controller, ARPN Journal of Engineering and Applied Sciences, VOL. 6, NO. 9, SEPTEMBER 2011, pp 55-62.

[3] G.SanthoshKumar, Brushless Dc Motor Speed Control Using Microcontroller, International Journal Of Current Engineering And Scientific Research (Ijcesr), Volume-2, Issue-2,2015, PP 182-188.

[4] Goutham Govind Raju, Mitigation of Torque for Brushless DC Motor: Modeling and Control, International Journal of Scientific \& Engineering Research Volume 3, Issue 5, May-2012, pp 1-5.

[5] Ashwini M. Welekar, Development of Brushless DC Motor Drive, IOSR Journal of Electrical and Electronics Engineering (IOSRJEEE), PP 12-18

[6] S.Khalid, B.Dwivedi, "Comparative Critical Analysis of Advanced Controllers used for Active Power Filter," National Conference on Power Electronics and Renewable Energy Systems, PEARES, Kalavakkam, 2009.

[7] Park ki-won, "A Review of active power filters", R\&D Center, POSCON.

[8] Zainal Salam, Tan Perng Cheng and Awang Jusoh, "Harmonics Mitigation Using Active Power Filter: A Technological Review", ELEKTRIKA, VOL. 8, NO. 2, 200.6, 17-26.

[9] Lucian Asiminoaei, Frede Blaabjerg, Steffan Hansen, "Evaluation of Harmonic Detection Methods for Active Power Filter Applications", Institute of Energy Technology, Denmark.

[10] P. Salmerón, R.S. Herrera," Instantaneous reactive power theory-A general approach to poly-phase systems", Electric Power Systems Research 79 (2009) 1263-1270. IEEE Guide for Application and Specification of Harmonic Filters, IEEE Standard, p. 1573, 2003.

\section{AUTHOR PROFILE}

Dr. K. RAMESH REDDY received B.Tech. in Electrical and Electronics Engineering from Nagarjuna University, Nagarjuna Nagar, India in 1985, M.Tech in Electrical engineering from National Institute of Technology (Formerly Regional Engineering College), Warangal, India in 1989, and Ph.D from SV University, Tirupathi, India in 2004. Presently he is working as Principal, G.Narayanamma Institute of Technology \& Science (For Women), Hyderabad, India. Prof. Ramesh Reddy is an author of more than 30 journal and conference papers, and author of two text books. His research and study interests include power quality, Harmonics in power systems and multi-Phase Systems.

S. V. D. ANIL KUMAR received B.Tech. in Electrical and Electronics Engineering from SV University, Tirupathi, India in 2000, M.Tech in Power Electronics from Visveswaraiah Technological university, Belgaum,India in 2005. He is Ph.D Student at Department of Electrical Engineering, JNT University, Hyderabad, India. Mr.S.V.D. Anil Kumar is an author of 15 journal and conference papers. His research and study interests include power quality, Harmonics in Power Systems 